\title{
Venous thrombosis in users of non-oral hormonal contraception: follow-up study, Denmark 2001-10
}

There is an error in the results section of this Research paper by Øjvind Lidegaard and colleagues (BMJ 2012;344:e2990, doi:10.1136/bmj.e2990). The second sentence should have read: "During this time 5287 diagnoses of first ever venous thrombosis events were recorded, corresponding to 5.6 per 10000 woman years [not "8.1 per 10000 woman years"]."

Cite this as: BMJ 2012;344:e3921

๑ BMJ Publishing Group Ltd 2012 